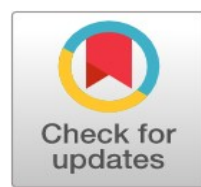

\title{
Transient analysis due to short circuit faults in wind hybrid systems
}

\author{
Farhana Umer ${ }^{1 *}$, Nurettin Cetinkaya ${ }^{2}$ \\ ${ }^{1,2}$ School of Electrical \& Electronics Engineering, Selcuk University, Konya, Turkey
}

\author{
Index Terms \\ Transient Analysis \\ Wind Farm \\ 3-Phase Short Circuit Fault \\ Fault Resistance \\ Overcurrent \\ Overvoltage \\ Fault Types \\ ATP/EMTP Software
}

Received: 8 April 2017

Accepted: 14 May 2017

Published: 30 June 2017

\begin{abstract}
The main aims of this paper are to analyse the short circuit transient behaviour of a grid connected hybrid power system (wind farm) and to offer suggestions for short circuits damages to be less affected. The hybrid power system in which conventional power system is integrated with wind farm is studied. In this research ATP/EMTP software is used for modelling of hybrid system integrated with wind generator and to simulate transient analysis of the 3- $\Phi$ Short Circuit Fault (SCF), line to ground fault and effect of fault resistance on conventional system and at Wind farm. The resulting transient over-voltages and currents has been computed \& plotted. The effect of Wind farm on conventional power system during faults has also been studied.
\end{abstract}

\section{INTRODUCTION}

The world's primary energy sources currently are fossil fuels and reserves of fossil fuel are reduced due to high dependence on it. So, we should use alternative energy sources; hydro, wind and solar are mostly used as renewable energy sources [1]. Figure 1 shows growth of the global electricity generation from 2012 to $2040.69 \%$ of total world electricity generation rises in 2016.

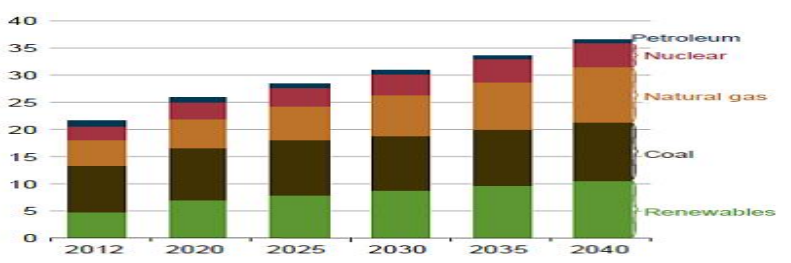

Fig. 1. World total electricity generation from 2012-2040 [2]

\footnotetext{
${ }^{*}$ Corresponding author: Farhana Umer
}

${ }^{\dagger}$ Email: farhana.umer@iub.edu.pk

Total generation increases by $2.9 \% /$ year from renewable resources and will grow $29 \%$ in 2040 . Figure 2 shows that hydro and wind energy each account for $33 \%$ and solar energy for $15 \%$ during projection period [2].

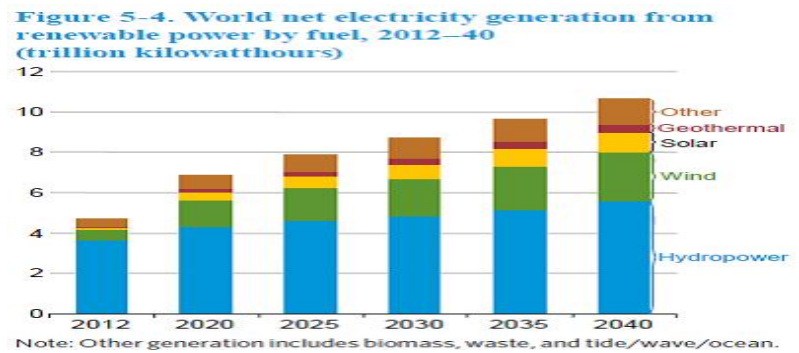

Fig. 2. Global net renewable energy generation by fuel type from 2012-2040 [2] 
Transient analysis due to faults in hybrid system is one of the most challenging and vital task. There are various causes of transients occur in power system, such as lightning strokes, component switching and due to faults. Power system transients creates a number of concerning and challenging problems, which includes accurate modelling of the power system at higher frequencies and the description of measured transient[3].

High frequency transients comprising frequencies from kilohertz to megahertz and these unfavourable phenomena may cause considerable damage in overstressing the insulation system, thermal stress and fire risk [4]. Transient in power system caused two types of stress i.e due to over-voltages, which can make flashover or breakdown of insulation and over-currents, which can damage equipment due to excessive heat dissipation [5].

The task of calculating SC current is not an easy task as in computing SC current for a Synchronous Generator (SG) in a conventional plant [6], [7]. In a SG magnetizing flux is controlled by the field current, thus, EMF driving the fault currents is accessible during the fault. While, in an induction generator the magnetizing flux is depleted during the fault and the fault currents are not sustainable for a long duration. Therefore, operation of hybrid power system with wind farm should be well planned. The power system switchgear and protection for wind farm should be carefully designed to be matched with the operation of conventional SG connected to the same grid [8].

EMTP/ATP software program is used to model wind hybrid power system as well as to simulate SCF. The resulting transient over-voltages and over-currents are computed and plotted as a result of the study. The aim of this research is to analysed transient behaviour of a hybrid power system (with Wind Farm) due to 3-phase short circuit faults. Transient analysis due to short circuit fault is extremely important for setting of protective relay and for the analysis of system operations. The system components are connected in cascade with a $400 \mathrm{kV}$ and $200 \mathrm{~km}$ long LCC line. The first power system studied is a conventional system (without Wind Farm), in which the transmission system is fed at one-end by a $S G$ as shown in Figure. 4. Various types of faults such as 3- $\omega$ SC and phase-to-ground faults are considered to take place at several bas-bars along a of a $400 \mathrm{kV} \mathrm{LCC}$ line. In this study several scenarios have been considered. These scenarios include the effect of 3-phase SCF at various locations, effect of fault resistance and fault type. The second power system studied is a hybrid system in which a conventional system is integrated with a $100 \mathrm{MW}$ wind farm. The effect of wind farm on the conventional power system during faults has also been studied.

\section{LITERATURE REVIEW}

Several researchers have been studied transient analysis of hybrid power systems due to faults, switching transient etc. Some of such studies are mentioned below.

In this work author presents contribution of SC current for various type of Wind generator. The resulted waveforms are analysed for understanding the behaviours i.e. rate of decay \& maximum value of WT. The consequences of the control algorithms of converters on SCF are also examined [8]. It has been shown in [9], that severity of fault and its transient component in transmission systems depends on several factors, such as the magnitude of voltage when fault occur, type of fault and fault location. These factors have important influence on magnitude and shape of voltage and current waveforms. Demetrios in [10] use the two-port theory based on symmetrical component transformation for the analysis of simultaneous faults in power systems. Similarly, LEVA applied time-dependent symmetrical components in [11] to study the dynamic analysis of asymmetrical faults in a power system. This approach explored Lyon state model of the faulted line to examine the transient overvoltages and current due to short circuit.

Barthold applied Bewley's lattice diagram in [12] to solve small networks, with linear and nonlinear lumpedparameter, as well as distributed-parameter elements. In recent year several modelling and solving techniques has emerged, and these have contributed tremendously toward gaining an insight into the nature of transient due to short circuit. Kang and Laver in [13] proposed state equation modelling which plays a vital role in electromagnetic transient simulation. Also Wavelet Transform used in [14] to examine switching and fault transient, complied with the preceded approaches.

Wilson and Schmidt in [15] analysed the behaviour of transmission line models for open circuit and short circuit. The voltage and current at any point on a line can be symbolized by both space and time dependent partial differential equations, and the solution of such equation become tedious especially when it involve a complex network. But the use of digital computers numerical methods has made the whole process easy and several methods have been developed.

Dommel combined the trapezoidal integration for lumped parameters and method of characteristics for transmission lines to solve power system transients [16], the 
trapezoidal rule is utilized to convert the differential equations of the network elements into algebraic equations regarding voltages and currents. However, numerous works has been accomplished in time and frequency domain to address some of the challenges.

The solution of a transient phenomenon is reliant on the initial conditions with which the transient commenced. Hybrid approaches to evaluate initial conditions in nonlinear networks using both time-domain and frequency techniques have also been developed [17]. Much advancement is emerging for the purpose of perfecting the entire transient studies, and these include optimization techniques. In [18] a Waveform matching technique is used based on Bare Bones Particle Swarm Optimization techniques of diagnosed short circuit fault.

Jafar Zangina Sulaiman worked on transient behaviour of a hybrid power system (wind and conventional power system) due to SC fault \& investigates the effect of type of fault and fault location. It's proved from the results that severity of fault transients in the power system studied varies on line length, source impedance \& fault location. The analysis carried out in this work is fundamental designing and operating stages of a hybrid system [19].

\section{METHOD OF ANALYSIS}

When the frequency dependence of the line parameters and the distributed nature of the losses are taken into account, it becomes very difficult, if not impossible in a practical way, to write the line equations directly in time domain. This solution, however, can easily be obtained in frequency domain, and is given by the well-known relations [22]. In this study, J Marti frequency-dependent model of transmission system with constant transformation matrix which is suited for simulating traveling wave phenomena in long lines has been adopted. It shows a good correlation with actual line responses [21].

\section{SYSTEM MODELS}

The studied Wind hybrid system is shown in Figure 3. A 1110 MVA SG supplies power to the bus of $400 \mathrm{kV}$ and 200 $\mathrm{km}$ long LCC line and. In this studied system $100 \mathrm{MW}$ Wind farm is connected at the mid point of the $400 \mathrm{kV}$ line [23]. In the conventional power system considered, SM59_NC type synchronous generator and two hybrid transformers are used, one of the transformers (XFMR) is used with conventional synchronous generator i.e $22 / 400 \mathrm{kV}$ and the second transformer is of $34.5 / 400 \mathrm{kV}$. In modern wind energy system, the most popular wind power generator used is Double
Fed Induction Generator (DFIG) because of its capability to operate at different variable speed ranges. The wind speed which derived the turbine is maintained constant at $12 \mathrm{~m} / \mathrm{s}$ [20].

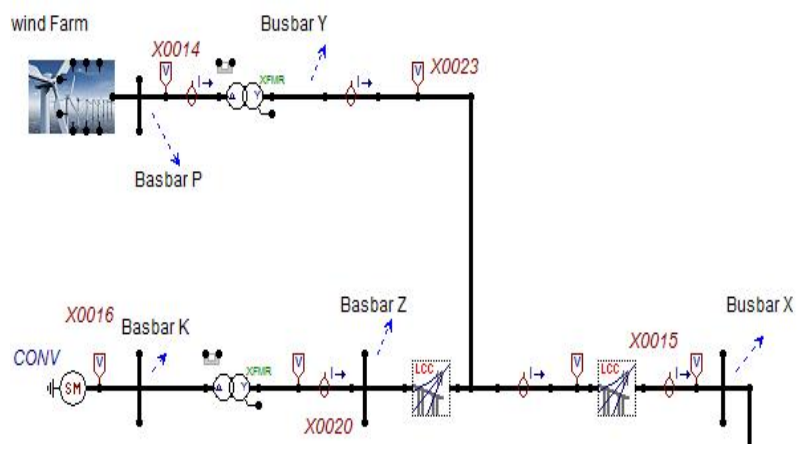

Fig. 3. Wind hybrid power system at no-load

\section{SYSTEM STUDIES}

In the research, the first studied system is a conventional system (without Wind farm). SCF takes place at the end of $400 \mathrm{kV}$ line. In this study, several scenarios have been considered, such as effects of fault location, fault resistance and the type of fault. The second studied system is a hybrid power system in which conventional power system is integrated with Wind Farm \& similar scenarios are considered also for the wind hybrid system.

\section{A. Modelling of Wind Farm}

Wind energy is a crucial part of the global drive for clean renewable energy substitute. The development of in wind power technology has provided advances in drive system, control systems. A wind farm is a group of wind turbines in the same location [24]. Wind turbine is categorised in terms of rotor configuration, and the wind speed at which a wind turbine starts to generate electricity is known as cutin speed while cut-out wind speed is the speed at which the rotor can damage [25]. Equation (1) is used for mechanical power delivered by the wind turbine.

$P_{w}=\frac{1}{2} C_{p}\left(\frac{R_{r}-n_{r}}{v}, \beta\right)$ pair $\pi R_{r}^{2} v^{3} \rightarrow 1$

Where;

pair : Air Density;

$R_{r}$ : Radius of turbine blade;

$\mathrm{v}$ : Wind speed respectively

$C_{p}$ : Rotor Power Coefficient;

$n_{r}$ : Turbine rotating speed in rpm;

$\beta$ : Blade Pitch angle 
In this research, a fixed speed squirrel cage induction generator (SCIG) is used as wind generator, similar to the one shown in Figure 4. Induction generates electricity when its speed is greater than synchronous speed. Wind turbine run in generator mode when its slip is negative. Normally slip of SCIG is between 0 and $-1 \%$, here in this study initial slip is $-0.388 \%$.

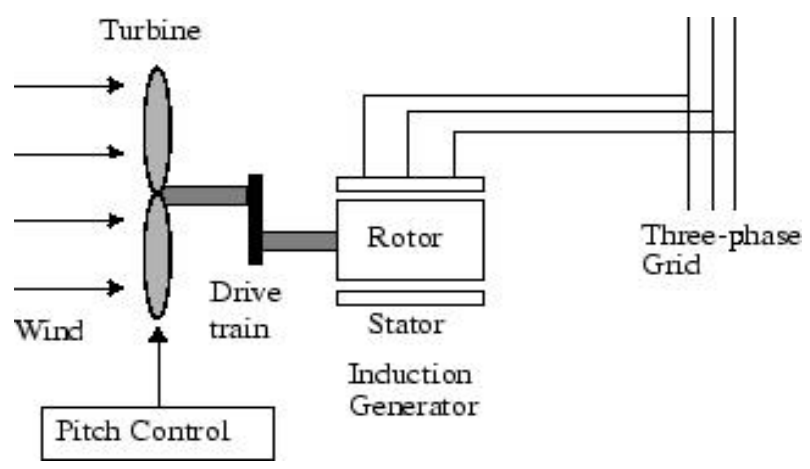

Fig. 4. Constant speed wind energy conversion system

\section{B. Effect of Location on Hybrid Power System with Wind Farm}

This section analysed the effect of 3-phase SCF at different location on hybrid system with Wind generator. 3-phase SCF occur at different location on Wind hybrid power system i.e. at bus-bar X, Y and Z respectively. SCF occurs when voltage of phase $\mathrm{A}$ at its peak value. Configuration of studied wind hybrid system is shown in Fig.5. Waveforms of currents for 3-phase SCF at bus-bars X, Y and $\mathrm{Z}$ are shown in Figs. 6 to 8 respectively.

It is observed from the results that magnitude of 3-phase SCF current is most severe when SCF occurs at basbar $\mathrm{Z}$ as compare to SCF occurs on other bus-bars. It is also observed that wave distortion is very high at bus-bar $\mathrm{Y}$ where, wind farm is interconnected with conventional system. Magnitude of 3-phase short circuit fault currents increases from $6.06 \mathrm{kA}$ to $11.03 \mathrm{kA}$ as shown on Table 1.

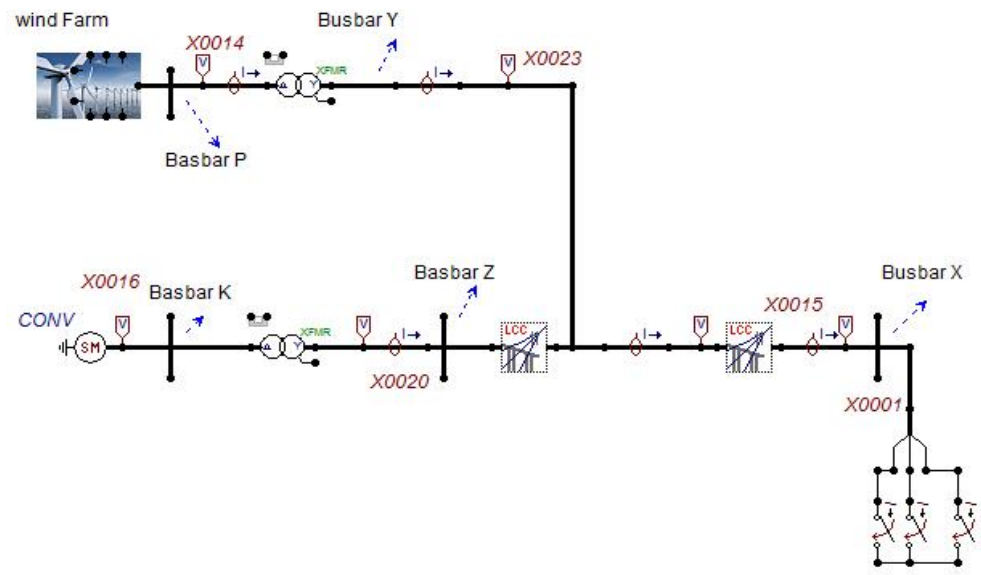

Fig. 5. Studied hybrid system with Wind Farm, when 3-phase SCF occur at bus-bar X

TABLE 1

Magnitude of 3-Phase short circuit fault (SCF) currents at different locations on hybrid power system

\begin{tabular}{llll}
\hline \hline Fault Location & \multicolumn{3}{l}{ Maximum Magnitude of 3-Phase Short Circuit Fault Currents (Amp) } \\
\hline & Phase A & Phase B & Phase C \\
\hline $\begin{array}{l}\text { 3-phase SCF occur } \\
\text { at bus-bar X }\end{array}$ & 6008 & 6060 & 5252 \\
$\begin{array}{l}\text { 3-phase SCF occur } \\
\text { at bus-bar Y }\end{array}$ & 8070 & 8255 & 7439 \\
$\begin{array}{l}\text { 3-phase SCF occur } \\
\text { at bus-bar Z }\end{array}$ & 11030 & 9840 & 8371 \\
\hline \hline
\end{tabular}




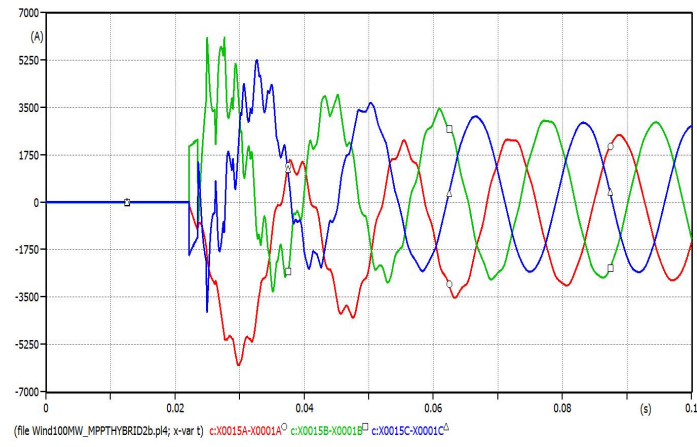

Fig. 6. Fault current at fault location, when 3-phase SCF occur at bus-bar X on hybrid system (with Wind farm)

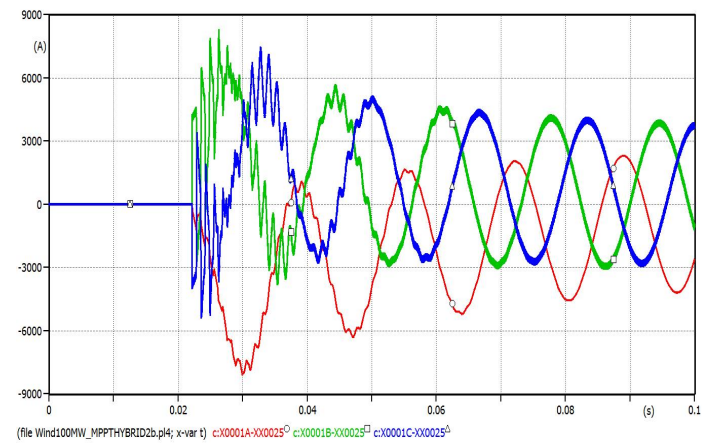

Fig. 7. Fault current at fault location, when 3-phase SCF occur at bus-bar Y on hybrid power system (with wind farm)

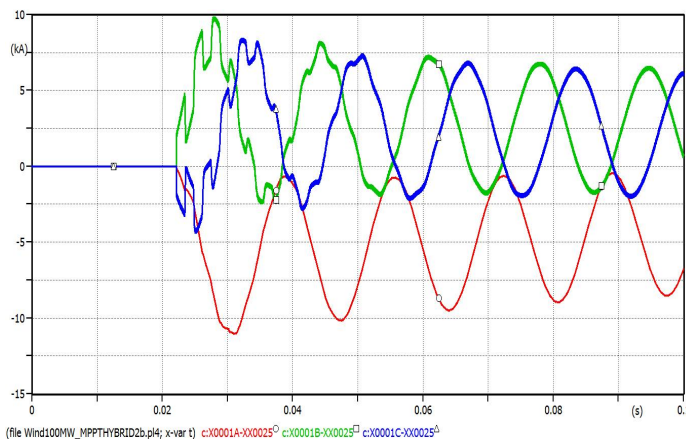

Fig. 8. Fault current at fault location, when 3-phase SCF occur at bus-bar $\mathrm{Z}$ on hybrid power system (with wind farm)

3-phase SCF occur at different location on hybrid power system, it also causes an effect on currents flowing through Wind farm i.e. bus-bar P. It is seen that effect of 3-phase SCF is most severe at meeting point of Wind farm, when SCF occurs at bus-bar Y as given on Table 2. It is also observed that wave attenuation is higher at bus-bar $\mathrm{P}$ when SCF occurs at bus-bar X and least at bus-bar $\mathrm{Y}$ as shown in Figs. 9 to 11 respectively. Table 2 shows the effect of 3-phase SCF at wind farm terminal and maximum magnitude of currents flow through Wind farm increases from 8.371 kA to $11.85 \mathrm{kA}$, when 3-phase SCF occur at different locations $\mathrm{X}$ to location $\mathrm{Z}$.

TABLE 2

Maximum magnitude of 3-phase short circuit fault (SCF) currents at wind farm (bus-bar P)

\begin{tabular}{|c|c|c|c|}
\hline Fault Location & \multicolumn{3}{|c|}{ Maximum Magnitude of 3-Phase Short Circuit Fault Currents (kA) } \\
\hline & Phase $\mathrm{A}$ & Phase B & Phase C \\
\hline 3-phase SCF occur at Bus-bar X & 8.371 & 4.204 & 7.797 \\
\hline 3-phase SCF occur at Bus-bar Y & 11.85 & 5.407 & 11.24 \\
\hline 3-phase SCF occur at Bs-bar Z & 11.24 & 5.760 & 10.59 \\
\hline
\end{tabular}

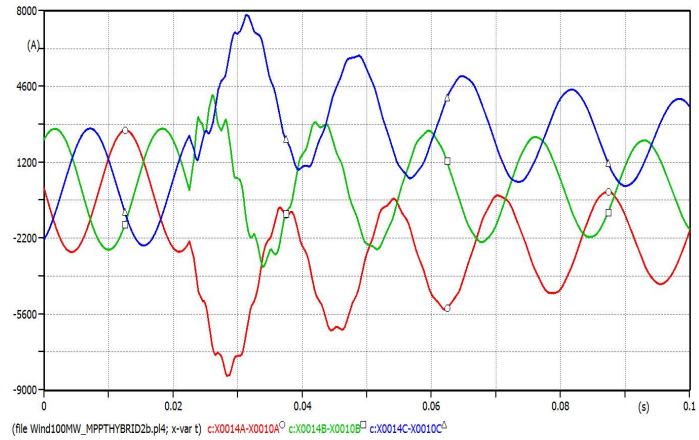

Fig. 9. 3-phase SCF currents at bus-bar P on wind farm terminal: when fault occurs at bus-bar X

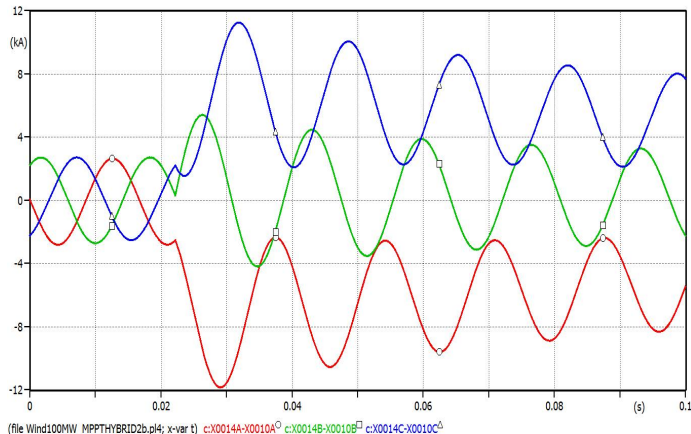

Fig. 10 . 3-phase SCF currents at bus-bar P on wind farm terminal: when fault occurs at bus-bar Y 


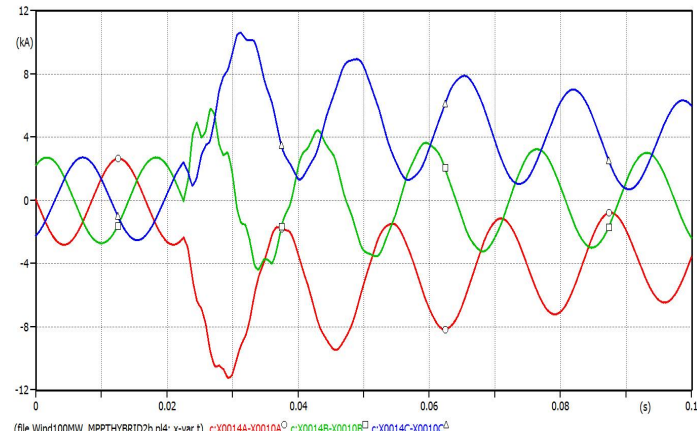

Fig. 11. 3-phase SCF currents at bas-bar P on wind farm terminal: when fault occurs at bus-bar $\mathrm{Z}$
Waveforms of 3-phase voltages at wind farm terminal (bus-bar P) due to short circuit fault at different locations on hybrid power system integrated with Wind farm are shown in Figs. 12 to 14. It is seen from the results given on Table 3 that 3-phase voltage reduces to lower value than rated voltage due to short circuit fault.

It is also seen that wave attenuation in voltage waveforms is very high when short circuit fault occurs at bus-bar $\mathrm{X}$ and its magnitude is least at meeting point of wind farm (bus-bar Y).

TABLE 3

Maximum magnitude of 3-phase short circuit fault (SCF) voltages at bus-bar P)

\begin{tabular}{llll}
\hline \hline Fault Location & \multicolumn{2}{c}{$\begin{array}{l}\text { Maximum Magnitude of 3-Phase Short Circuit Fault Voltages (kV) } \\
\text { Phase A }\end{array}$} & $\begin{array}{l}\text { Phase B } \\
\text { Phase C }\end{array}$ \\
\hline $\begin{array}{l}\text { 3-phase SCF occur } \\
\text { at bus-bar X }\end{array}$ & 24.65 & 32.78 & 19.82 \\
$\begin{array}{l}\text { 3-phase SCF occur } \\
\text { at bus-bar Y }\end{array}$ & 4.802 & 8.85 & 21.1 \\
$\begin{array}{l}\text { 3-phase SCF occur } \\
\text { at bus-bar Z }\end{array}$ & 18.57 & 28.5 & 17.27 \\
\hline \hline
\end{tabular}

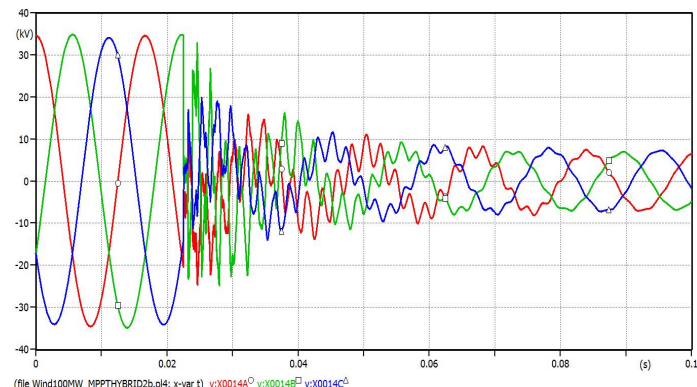

Fig. 12 . 3-phase voltage at bus-bar P: when SCF occurs at bus-bar X

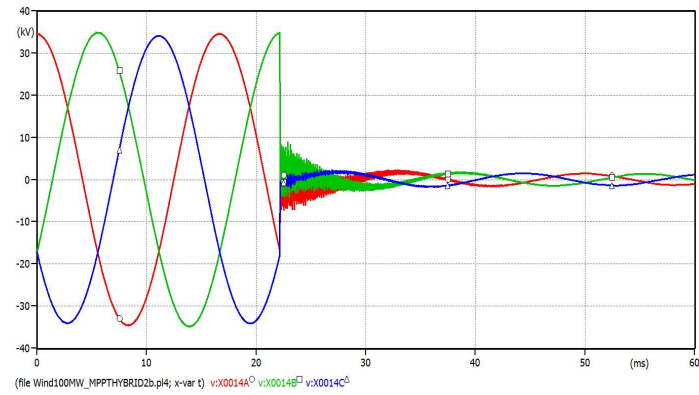

Fig. 13 . 3-phase voltage at bus-bar P: when SCF occurs at bus-bar Y

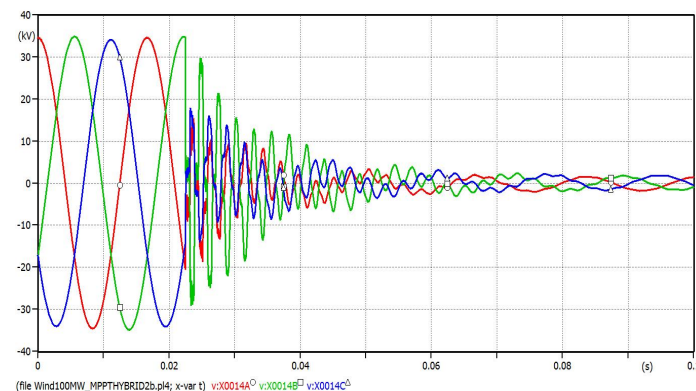

Fig. 14 . 3-phase voltage at bus-bar P: when SCF occurs at bus-bar Z

\section{Effect of Fault Resistance on Hybrid System (with Wind Farm)}

In this section effect of fault resistance due to different types of fault i.e. single line to ground fault and short circuit fault is studied.

\section{Effect of Location on Hybrid Power System with Wind Farm}

Types of fault: A line to earth fault is considered to take 
place on phase A at bus-bar X on the line as shown in Fig.15. Single line to earth fault occurs when voltage of phase A is at peak value i.e. at $18.14 \mathrm{msec}$. The length of transmission line between bus-bars X and Z (at $400 \mathrm{KV}$ ) is 200 $\mathrm{km}$. The current waveforms of faulted phase at bus-bars X and $\mathrm{Z}$ are computed and plotted for various fault resistance varying from $1 \Omega$ to $100 \Omega$ both at bus-bars X and Z. The waveforms of the fault currents are shown in Figs. 16-17 for conventional power system alone and hybrid power system (with Wind farm), respectively. The maximum values of the faulted phase currents at sending end i.e., at bus-bar $\mathrm{Z}$ and at the fault location i.e., at bus-bar $\mathrm{X}$ are given on Tables 4 and 5 , respectively for different fault resistance. The simulation results show that the maximum magnitude of the currents at bus-bar $\mathrm{Z}$ and fault location $\mathrm{X}$ decreases as the line fault resistance increases. Also ripples along the line attenuate as fault resistance decreases. For hybrid power system, fault current at fault location X decreases starting from $2108 \mathrm{Amp}$ up to $1275 \mathrm{Amp}$, as shown on Table 4; fault current at location $\mathrm{Z}$, however varies from $1842 \mathrm{Amp}$ up to $1280 \mathrm{Amp}$ as shown on Table 5. So, it can be seen that fault currents at fault location $\mathrm{X}$ is much larger in case of hybrid power system compared to those which flow in case of conventional power system alone. But at location $\mathrm{Z}$ fault current is much smaller in case of hybrid power system (with Wind farm) comparing to those which flow in case of conventional power system alone.

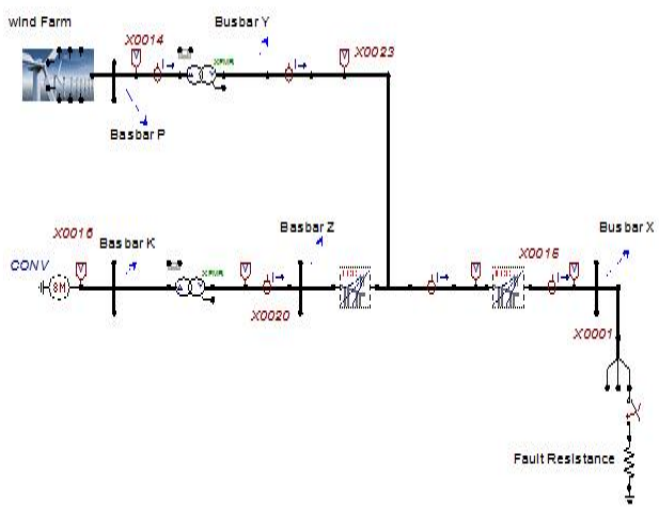

Fig. 15. Studied hybrid power system (with Wind Generator) with various fault resistance: when line to ground fault occurs on phase A at bus-bar X

TABLE 4

Maximum magnitude of fault current at fault location (bus-bar X)

\begin{tabular}{lll}
\hline \hline Fault Resistance $(\Omega)$ & $\begin{array}{l}\text { M aximum Magnitude of Fault Current at Fault Location (Amp) } \\
\text { Conventional Power } \\
\text { System Alone }\end{array}$ & $\begin{array}{l}\text { Hybrid Power Sys- } \\
\text { tem (With Wind } \\
\text { Farm) }\end{array}$ \\
& & 2108 \\
1 & 1742 & 2024 \\
5 & 1699 & 1926 \\
10 & 1649 & 1756 \\
20 & 1561 & 1415 \\
50 & 1365 & 1275 \\
100 & 1159 & \\
\hline \hline
\end{tabular}

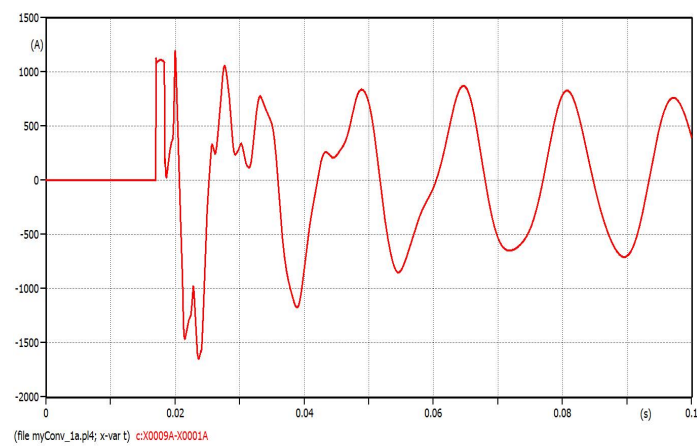

Fig. 16. Fault Current at fault location X: when fault resistance is $10 \Omega$ on conventional power system alone (a)

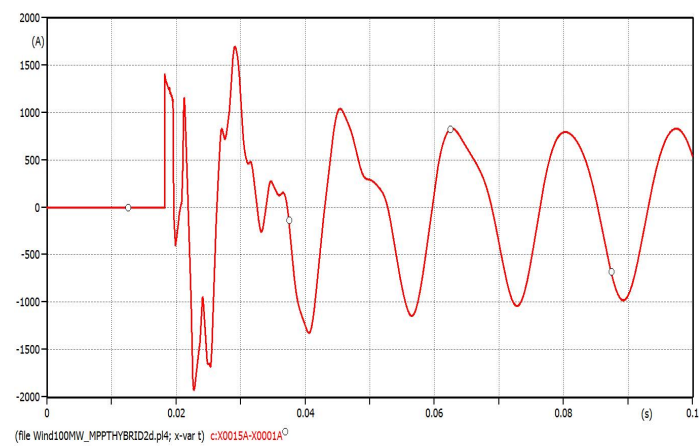

Fig. 17. Fault Current at fault location A when fault resistance is $10 \Omega$ on hybrid power system (with Wind farm) (b) 
TABLE 5

Maximum magnitude of fault current at bus-bar $\mathrm{Z}$

\begin{tabular}{lll}
\hline \hline Fault Resistance $(\Omega)$ & M aximum Magnitude of Fault Current at Point C (Amp) \\
\hline & $\begin{array}{l}\text { Conventional Power } \\
\text { System Alone }\end{array}$ & $\begin{array}{l}\text { Hybrid Power Sys- } \\
\text { tem (With Wind } \\
\text { Farm) }\end{array}$ \\
\hline 1 & 2136 & 1842 \\
10 & 2051 & 1764 \\
20 & 1966 & 1686 \\
50 & 1753 & 1499 \\
100 & 1499 & 1280 \\
\hline \hline
\end{tabular}

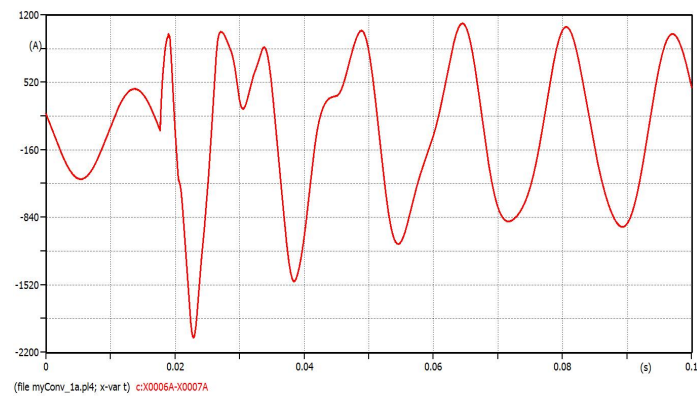

Fig. 18. Fault Current at bus-bar Z: when fault resistance is $10 \Omega$ on conventional power system alone (a)

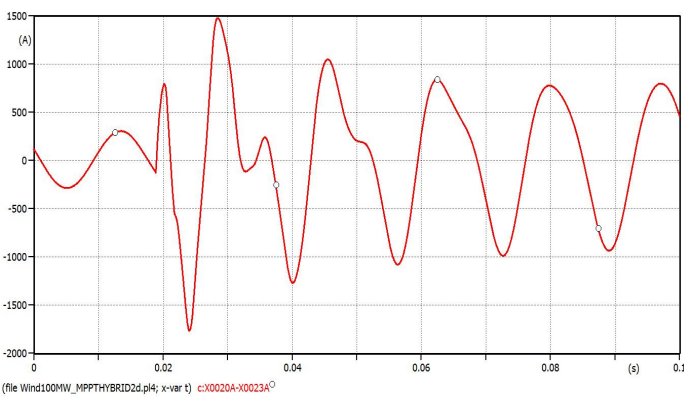

Fig. 19. Fault Current at location $\mathrm{C}$ when fault resistance is $10 \Omega$ on hybrid system (b)

TABLE 6

Voltages at bus-bar Z and fault location $\mathrm{X}$

\begin{tabular}{|c|c|c|c|c|}
\hline & \multicolumn{2}{|r|}{$\mathrm{H}$} & \multicolumn{2}{|c|}{ ybrid Power System (With Wind Farm) } \\
\hline & & & \multirow{4}{*}{$\begin{array}{l}\text { Maximum Mag- } \\
\text { nitude of Fault } \\
\text { Voltage at bs-bar Z } \\
(\mathrm{MV})\end{array}$} & \multirow{4}{*}{$\begin{array}{l}\text { Maximum Mag- } \\
\text { nitude of Fault } \\
\text { Voltage at Fault } \\
\text { Location X (MV) }\end{array}$} \\
\hline & & & & \\
\hline & & & & \\
\hline & & & & \\
\hline & Phase & Phase & Phase B & Phase C \\
\hline & B & $\mathrm{C}$ & & \\
\hline 1 & 1.215 & 1.115 & 1.09 & 1.132 \\
\hline 10 & 1.17 & 1.076 & 1.061 & 1.106 \\
\hline 50 & 1.018 & 1.007 & 0.9678 & 1.014 \\
\hline 100 & 0.8897 & 0.9551 & 0.8668 & 0.938 \\
\hline
\end{tabular}

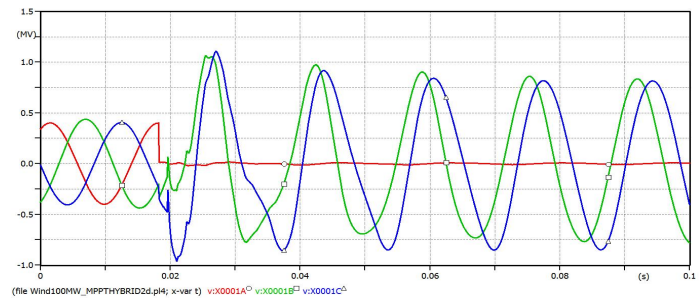

Fig. 20 . 3-phase voltage at fault location $\mathrm{X}$ on hybrid power system (with wind farm): when fault resistance is $10 \Omega$

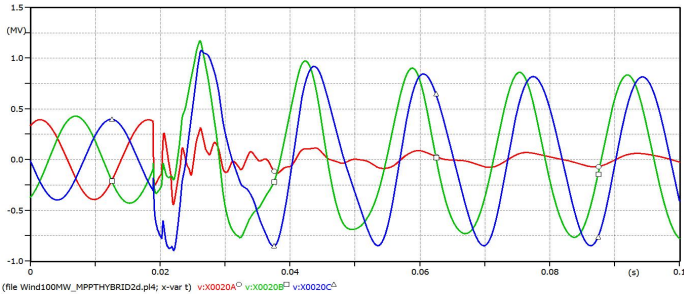

Fig. 21 . 3-phase voltage at bus-bar $\mathrm{Z}$ on hybrid power system (with wind farm): when fault resistance is $10 \Omega$ 
Voltage waveforms of un-faulted phases B and C at fault location $\mathrm{X}$ and $\mathrm{Z}$ are shown in Figs. 18 \& 19. Voltage of un-faulted phases increases at both location $\mathrm{X}$ and $\mathrm{Z}$ on hybrid power system (with Wind farm) and voltage of faulted phase drops to zero at fault location $\mathrm{X}$ but at location $\mathrm{Z}$ it drops to minimum value less than rated voltage as given on Table 6. It is also observed that wave attenuation is least at fault location $\mathrm{X}$ but it is higher at bus-bar $\mathrm{Z}$.

Now considered 3-phase short circuit fault with fault resistance takes place at the end of line on hybrid system (with Wind farm). The current waveforms of 3-phase at fault location are computed and plotted for fault resistances $1 \Omega, 20 \Omega, 50 \Omega$ and $100 \Omega$ at fault locations X. The wave- form of the 3- $\omega$ SCF current is shown in Fig. 20 for hybrid power system (with Wind farm). The maximum values of the faulted phase currents at fault location $X$ are given on Table 7 for various fault resistances. The simulation results show that the maximum magnitude of the current at fault location decreases as fault resistance increases. For hybrid power system, maximum magnitude of short circuit fault current at location X decreases starting from 6193 Amp up to 2580 Amp, as given on Table 7. It can also be seen that fault currents due to 3-phase SCF location X are much larger in case of hybrid power system compared to those which flow in case of line to ground fault on hybrid power system.

TABLE 7

Maximum magnitudes of faulted phase currents at fault location X on hybrid system due to line to ground fault and 3-phase short fault (SCF) for various fault resistance

\begin{tabular}{lllll}
\hline \hline $\begin{array}{l}\text { Fault Resistance Rf } \\
(\Omega)\end{array}$ & & M & \multicolumn{2}{l}{ aximum Magnitude of Fault Current (Amp) } \\
& L-G Fault & & $\begin{array}{l}\text { 3- } \omega \text { Short Circuit } \\
\text { Fault }\end{array}$ \\
\hline & Phase B & Phase C & Phase B & Phase C \\
\hline 1 & 2108 & 4995 & 6193 & 5787 \\
10 & 1926 & 4481 & 5436 & 5005 \\
20 & 1756 & 3998 & 4797 & 4556 \\
50 & 1415 & 2989 & 3570 & 3535 \\
100 & 1275 & 2373 & 2580 & 2532 \\
\hline \hline
\end{tabular}

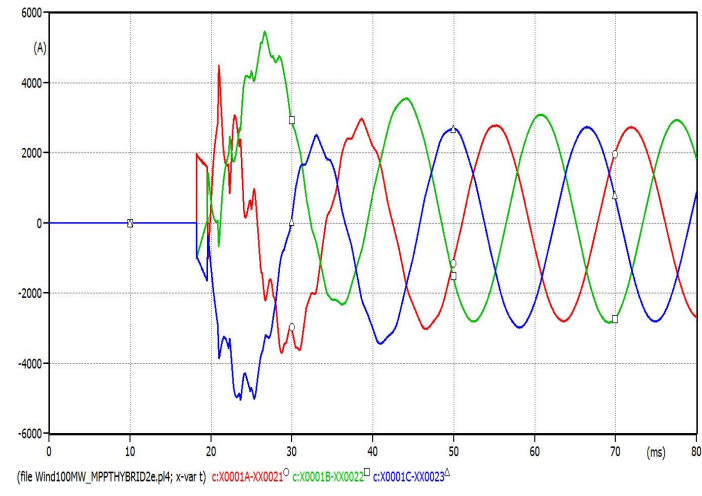

Fig. 22 . 3- $\omega$ SCF current on hybrid power system (with Wind farm): when fault resistance is $10 \Omega$

\section{DISCUSSION ON RESULTS}

Jaffar in [20] studied transient analysis on wind hybrid system and and used $20 \mathrm{~km}$ long line length for $132 \mathrm{kV}$ system. For this short line length transient in power sys- tem is very high while in my research I used $200 \mathrm{~km}$ long length for $400 \mathrm{kV}$ system and here transient at $200 \mathrm{~km}$ long line length is very less as compare to [20].

Secondly author in [8] studied transient due to different types of wind generator and for variable speed. It is observed that variability of wind speed also contribute for transient and wave distortion on current and voltage waveforms so, in my research we tried to run generator at constant speed so transient of current and voltage waveforms is reduced [27].

\section{CONCLUSION}

This research work is significant for designing, planning, and operation of hybrid power systems. These studies are important as they have a direct bearing on the insulation requirements, cost and reliability of the designed network. ATP/EMTP software is used to carry out this study. The data of transient fault currents computed for various types of faults are of importance in the design of protective 
schemes. It has been proved from the results that severity of transient over-currents due to SCF in the wind hybrid system varies depending on the fault type, fault resistance and fault location. These factors have considerable effects on the magnitudes and shapes of the current and voltage waveforms.

From the waveforms obtained it is observed that as fault resistance increases, the magnitudes of maximum fault currents are decreased. It is also seen from the results that when Wind farm is interconnected to the conventional power system, maximum magnitude of the fault current and attenuation in the current waveforms become considerable compared to those obtained in the case of conventional power system alone [28]. For hybrid power system, fault current at fault location $\mathrm{X}$ decreases starting from $2108 \mathrm{Amp}$ up to $1275 \mathrm{Amp}$ and fault current at location Z, however varies from $1842 \mathrm{Amp}$ up to $1280 \mathrm{Amp}$, So, it can be seen that fault currents at fault location $X$ is much larger in case of hybrid power system compared to those which flow in case of conventional power system alone. The maximum magnitude of fault currents obtained due to three- phase SCF is much more as compared to other type of faults on hybrid power system. Magnitude of 3-phase short circuit fault currents increases from $6.06 \mathrm{kA}$ to $11.03 \mathrm{kA}$. The maximum magnitudes of transient fault currents are observed to be considerably higher at interconnection point of Wind farm and conventional system fault point along the transmission line. Maximum magnitude of currents flow through Wind farm increases from $8.371 \mathrm{kA}$ to $11.85 \mathrm{kA}$, when 3-phase SCF occur at different locations X to location Z. Voltage waveforms are decreased to smaller value than rated voltage on hybrid power system (with Wind farm). Also wave attenuation increases as it come closer to source location.

\section{REFERENCES}

[1] B. Bhandari, K. T. Lee, G. Y. Lee, Y. M. Cho and S. H. Ahn, "Optimization of hybrid renewable energy power systems: A review," International Journal of Precision Engineering and Manufacturing-Green Technology, vol. 2, no. 1, pp. 99-112, 2015. DOI: 10.1007/s40684-015-0013-z

[2] International Energy Outlook, "Energy information administration (EIA)," 2016 [Online]. Available: http://www.eia.doe.gov/iea

[3] M. H. Bollen, E. Styvaktakis and I. Y. H. Gu, "Categorization and analysis of power system transients," IEEE Transactions on Power Delivery, vol. 20, no. 3, pp. 2298-2306, 2005. DOI: 10.1109/TPWRD.2004.843386

[4] D. Smugala, W. Piasecki, M. Ostrogorska, M. Florkowski, M. Fulczyk and 0. Granhaug, "Wind turbine transformers protection method against high-frequency transients," IEEE Transactions on Power Delivery, vol. 30, no. 2, pp. 853-860, 2015.

[5] J. A. Martinez-Velasco, ed., Transient Analysis of Power Systems: Solution Techniques, Tools and Applications. New York, NY: John Wiley \& Sons, 2014.

[6] International Electrotechnical Commission, ShortCircuit Currents in Three-Phase AC Systems. Geneva, Switzerland: Commission Electrotechnique Internationale International Electrotechnical Commission, 2001.

[7] IEEE Standard, EEE Application Guide for AC HighVoltage Circuit Breakers Rated on a Symmetrical Current Basis. New York, NY: The Institute of Electrical and Electronics Engineers, Inc., 2000.

[8] E. Muljadi, N. Samaan, V. Gevorgian, J. Li and S. Pasupulati, "Short circuit current contribution for different wind turbine generator types," in IEEE Power and Energy Society General Meeting, Providence, RI, 2010. DOI: $10.1109 /$ PES.2010.5589677

[9] M. Uğur Ünver, "Short-circuit fault analysis of transmission lines: double end fed system (in Turkish)," 1995.

[10] D. Tziouvaras, Analysis of Complex Power System Faults and Operating Conditions. Pullman, WA: Schweitzer Engineering Laboratories, Inc., 2008.

[11] S. Leva, "Power network asymmetrical faults analysis using instantaneous symmetrical components," Journal of Electromagnetic Analysis and Applications, vol. 1 , no. 04, pp. 205-213, 2009 . DOI: $10.4236 /$ jemaa.2009.14031

[12] L. O. Barthold and G. K. Carter, "Digital traveling-wave solutions I-Single-phase equivalents," Transactions of the American Institute of Electrical Engineers. Part III: Power Apparatus and Systems, vol. 80, no. 3, pp. 812-818, 1961. DOI: 10.1109/AIEEPAS.1961.4501145

[13] Y. Kang and J. D. Lavers, "Transient analysis of electric power systems: Reformulation and theoretical basis," IEEE Transactions on Power Systems, vol. 11, no. 2, pp. 754-760, 1996. DOI: $10.1109 / 59.496150$

[14] P. Thoratand S. Turkane, "Detection of capacitor switching transients and LG fault transients by implementing wavelet transform," IOSR Journal of Electrical and Electronics Engineering, vol. 2, no. 5, pp. 39-42, 2012. DOI: 10.9790/1676-0253942 
[15] G. L. Wilson and K. A. Schmidt, "Transmission line models for switching studies: Design criteria II. Selection of section length, model design and tests," IEEE Transactions on Power Apparatus and Systems, vol. 1, pp. 389-395, 1974. DOI: 10.1109/TPAS.1974.293959

[16] H. W. Dommel, "Digital computer solution of electromagnetic transients in single-and multiphase networks," IEEE Transactions on Power Apparatus and Systems, vol. 4, pp. 388-399, 1969. DOI: 10.1109/TPAS.1969.292459

[17] G. Murere, S. Lefebvre and X. D. Do, "A generalized harmonic balance method for EMTP initialization," IEEE Transactions on Power Delivery, vol. 10, no. 3, pp. 1353-1359, 1995. DOI: 10.1109/61.400916

[18] R. Phukan, R. K. Gupta, S. Dadga and A. Rathinam, Fault diagnosis of a high voltage transmission line using waveform matching approach," International Journal on Soft Computing, vol. 4, no. 4, pp. 33-50, 2013. DOI: 10.1109/TPAS.1969.292459

[19] J. F. Z. Sulaiman, "Transient analysis of short circuit faults in a hybrid power system. Doctoral dissertation, Mevlana University, Konya, Turkey, 2014.

[20] E. M. T. P. Leuven, Center, ATP-Alternative Transient Program-Rule Book. Herverlee, Belgium: EMTP Center, 1987

[21] J. R. Marti, "Accuarte modelling of frequency-dependent transmission lines in electromagnetic transient sim- ulations," IEEE Transactions on Power Apparatus and Systems, vol. 1, pp. 147-157, 1982. DOI: 10.1109/TPAS.1982.317332

[22] R. Valarmathi, S. Palaniswami and N. Devarajan, "Simulation and analysis of wind energy and photo voltaic hybrid system," International Journal of Soft Computing and Engineering, 2(2), 193-200, 2012.

[23] M. R. Patel, Wind and Solar Power Systems. Florida, FL: CRC Press LLC, 1999.

[24] G. M. Masters, Renewable and Efficient Electric Power Systems. New York, NY: John Wiley \& Sons, Inc., 2004. DOI: $10.1002 / 0471668826$

[25] J.G. Slootweg, "Wind power: modelling and impact on power system dynamics," $\mathrm{PhD}$ dissertation, Department of Electrical Engineering, Delft University of Technology, Delft, Netherlands, 2003.

[26] K. Marat, Y. Assem, M. Bakhytzhan and K. Peter, "Theoretical and experimental researches on development of new construction of wind-driven generator with flux concentrator," Journal of Advances in Technology and Engineering Research, vol. 2, no. 3, pp. 100-104, 2016. DOI: $10.20474 /$ jater-2.3.1

[27] S. N. Singh, V. S. Prathiba, R. R. Singh and S. R. Lenka, "A roof top utility interfaced PV power system for rural India," International Journal of Technology and Engineering Studies, vol. 2, no. 1, pp. 13-18, 2016. DOI: 10.1016/j.lwt.2008.04.002 


\section{APPENDIX}

\begin{tabular}{ll}
\multicolumn{2}{c}{ Appendix } \\
\hline \hline \multicolumn{2}{c}{ Wind Generator (IM56A) } \\
\hline L-L Voltage(KV) & 34.5 \\
Power (MW) & 100 \\
Rated Frequency & $60 \mathrm{~Hz}$ \\
Poles & 2 \\
Initial Slip & -0.3889 \\
$R_{-} S(\mathrm{pu})$ & 0.037 \\
$L_{S}$ & $(\mathrm{pu}) 0.07$ \\
$R_{R}$ & $(\mathrm{pu}) 0.018$ \\
$L_{R}(\mathrm{pu})$ & 0.03 \\
\hline \hline
\end{tabular}

\section{Synchronous generator:}

$\mathrm{S}=1110 \mathrm{MVA}, \mathrm{V}=22 \mathrm{kV}, \mathrm{f}=60 \mathrm{~Hz}$, Poles $=2, R_{A}=0.0036, X_{L}=0.13, X_{d}=1.933, X_{q}=1.743, X_{d}^{\prime}=0.467, X_{q}^{\prime}=1.144, X_{d}^{\prime \prime}$ $=0.312, X_{q}^{\prime \prime}=0.312, T_{d 0}^{\prime}=6.66, T_{q 0}^{\prime}=0.44, T_{d 0}^{\prime \prime}=0.032 \& T_{q 0}^{\prime \prime}=0.057$

\section{JMarti Transmission Line:}

$\mathrm{V}=400 \mathrm{kV}, \mathrm{f}=60 \mathrm{~Hz}$, Line Length $=200 \mathrm{~km}$, Resisitivity of Soil $=20 \Omega-\mathrm{m}, \mathrm{Z}=0.0807+\mathrm{j} 0.2523 \Omega / \mathrm{km}$, Shunt Admittan $=-$ $6 e^{(-5)}+\mathrm{j} 0.0177 \mu \mathrm{F} / \mathrm{km}$

Hybrid Transformer $\mathrm{T}_{1} \& \mathrm{~T}_{2}$

\begin{tabular}{ll}
\multicolumn{2}{c}{ Hybrid Transformer $\mathrm{T}_{1} \& \mathrm{~T}_{2}$} \\
\hline \hline \multicolumn{2}{c}{ Wind Generator (IM56A) } \\
\hline Hybrid Transformer T1 & $22 / 400(\Delta-\mathrm{Y})$ \\
L-L Voltage(KV) & 1110 \\
Power (MVA) & $60 \mathrm{~Hz}$ \\
Test Frequency & 3 leg stacked \\
Type of Core & 2 \\
Number of Windings & $13.7881 \mathrm{nF}$ \\
C P-G & $4.6316 \mathrm{nF}$ \\
C S-G & $1.9849 \mathrm{nF}$ \\
C m & \\
Hybrid Transformer $\mathbf{T}_{2}$ & $34.5 / 400(\Delta-\mathrm{Y})$ \\
L-L Voltage(kV) & 110 \\
Power (MVA) & $60 \mathrm{~Hz}$ \\
Test Frequency & 3 leg stacked \\
Type of Core & 2 \\
Number of Windings & $27.87 \mathrm{nF}$ \\
C P-G & $6.22 \mathrm{nF}$ \\
C S-G & $2.66 \mathrm{nF}$ \\
C m & \\
Where, & \\
P-G : Capacitance between the primary winding and the ground & \\
S-G : Capacitance between the secondary winding and the ground & \\
P-G : Mutual capacitance between the primary and secondary winding & \\
\hline \hline
\end{tabular}

